\title{
Article \\ The Service Innovation Factor in Painting Creation Enterprises from the Service-Dominant Logic Perspective
}

\author{
Szu-Yao Lin (D)
}

check for updates

Citation: Lin, S.-Y. The Service Innovation Factor in Painting Creation Enterprises from the Service-Dominant Logic Perspective. Appl. Syst. Innov. 2022, 5, 16. https:// doi.org/10.3390/asi5010016

Academic Editor: Christos Douligeris

Received: 2 December 2021

Accepted: 13 January 2022

Published: 24 January 2022

Publisher's Note: MDPI stays neutral with regard to jurisdictional claims in published maps and institutional affiliations.

Copyright: (C) 2022 by the author. Licensee MDPI, Basel, Switzerland. This article is an open access article distributed under the terms and conditions of the Creative Commons Attribution (CC BY) license (https:// creativecommons.org/licenses/by/ $4.0 /)$
Graduate School of Creative Industry Design, National Taiwan University of Arts, New Taipei City 22058, Taiwan; cynszlin@gmail.com

\begin{abstract}
This paper describes a study of the elements of service innovation for artistic painting creation enterprises from the service-dominant logic point of view. This research mainly aimed to (1) explore how to integrate the concepts of service innovation for companies (service provider) providing painting as their service in their business model, and (2) to explore that how consumers (service receiver) can evaluate their experience value as well as achieve value co-creation through the service process under the service innovation model. Here, a multiple case-detailed CEO-interviewbased methodology was used with four corporate companies that provide artistic painting creation services. The findings showed that, as painting is the core content of the service, the process not only meets the emotional needs of consumers through its operations, but also develops innovations in the business model to solve social issues. This research applies the viewpoint of art in the service science field and combines creative and innovative thinking with business operations. The outcome has practical implications for enhancing the social value of business structures and enabling value cocreation under the development of creative industries. In conclusion, the popularity and accessibility of using painting as a service reinforces painting creation to develop internal expression channels that can be used as service innovation for the development of businesses in the creative industries.
\end{abstract}

Keywords: service innovation; painting creation; service-dominant logic; value co-creation; experience economy; social innovation

\section{Introduction}

Nowadays, speed is the standard pursued. The pursuit of efficiency in all areas is making social community life increasingly compact. The stress experienced by individuals on a daily basis in modern society is also continually increasing; furthermore, stress is the key factor causing emotions. Dealing with emotions has become an important topic for everyone in modern society. As such, a wave of business models has focused on social and economic healing in recent years. The purpose of healing is to achieve emotional soothing through business models. It has led to the creation of various new healing economies, one of which is the creation of paintings, which has led to market development and the formation of a brand-new service.

Tolstoy said: "Art begins when a man, with the purpose of communicating to other people, a feeling he once experienced, calls it up again within himself and expresses it by certain external signs" [1]. The healing produced through the creation of paintings does not lie in the quality of the work or its beauty, but in the process of experience. It is the process of nonverbally feeling the state of oneself. There are now industries that are based on the creation of paintings, for example, a popular brand called "Paint and Sip", which sells group painting lessons accompanied by wine or other beverages in European and North American countries. There are other various studios and art workshops promoting stress relaxation. In recent years, companies that provide healing and stress-relieving services have begun to emerge in the markets around the world. These services that are providing spiritual comfort not only let people relieve stress and relax, but also allow people to 
learn new skills or cultivate interests. The consumer experience of these services meets their spiritual needs; the humanized services resonate with consumers who project their own emotional feelings into the experience process. This industry enhances the value of experience and affects consumers' lifestyles. The process of creating a painting provides a channel for individuals to unconsciously express their inner self. Through painting, people can learn from experiences of their inner state. The process of painting creation can also lead to the creation of emotional stability and balance, and even promote self-growth.

Social innovation has emerged to solve a certain problem experienced by enterprises in society or social organizations. These social enterprises are diversified due to their value propositions. The system of the society in which the enterprise is located and the government's implementation of the policies have also led to the differences in these enterprises. The concept of social innovation in Taiwan has gradually penetrated the public's consciousness. However, there is still room for development of enterprise evaluation standards in various categories. Currently, the enterprises that provide healing services through the creation of paintings in Taiwan are more targeted at specific groups of people, such as using art therapy for psychotherapy. Or, the business models are biased toward traditional profit-making, such as those of regular art studio or workshops. There is a lack of clear and standardized business evaluation indicators in various industries. Therefore, the lack of core values and resource integration for long-term business operation are the main issues that need to be addressed. However, from the perspective of social innovation, there is an advantage to the potential in the healing industry. The enterprises offering painting creation can not only find suitable solutions to the existing social issue of emotional stress, but also combine the characteristics of effectiveness, efficiency, and sustainability to continually create and deliver social value [2]. Furthermore, painting creation has economic and social co-creation value that is worthy of further discussion regarding the positive social influence exerted by and on the public.

The concept of service innovation enables the service network to allow all the actors or participants to co-create value, thereby integrating consumers, organizations, and the public in the business model of the enterprise in playing this important role [3]. From a social point of view, service innovation is a method of creating and developing the actor's own value, of improving the social ecological environment, and of constructing a suitable service experience and innovation process by considering appropriate execution tools in the service design process.

An important issue in the field of service design is related to social innovation. In recent years, studies in the service science field have focused on service innovation and service design. Research has shown that service design can further promote service innovation. However, current studies mostly focused on concepts and theories; more practical research on the processes and implications is needed [4,5]. Regarding service innovation in the development of new value propositions, it is crucial to discuss the key role of service design and its relationships as society has entered the era of the experience economy. Regardless of whether the business model is based on products or services, the service experience process is an important aspect of any business. Research has also emphasized the criticality of service design under various business models.

The aim of this research was to explore the elements of service innovation of companies providing painting creation as their service offer from the service-oriented logic point of view. By analyzing the results of case interviews with corporate entities, the findings show how painting creation is the service offer, how the emotional needs of consumers are met through its operations, and how innovations are developed in their business models to solve social issues. These innovations also allow the organization to operate continuously based on the internal and external co-creation of value, and they can have a positive social influence on the general public. The impact of this research is in a description of the factors that influencing the popularity of art creation and its open accessibility to the public. The use of painting creation involves internal expression, which is a social service innovation model that shows potential for development. 
Therefore, the objectives of this study were as follows:

1. to explore the relationships and connotation of service innovation with the firm specific advantages from the enterprises offering creation of paintings,

2. to construct a service innovation model for enterprises offering creation of paintings and

3. to analyze the service experiences and effectiveness that can co-create values in the service process for businesses offering creation of painting.

\section{Theoretical Background}

\subsection{Art Creation and Social Innovation in Art}

Art is characterized by diversity, tolerance, and creativity. From ancient times to the present, the high degree of human acceptance of art also demonstrates its sustainability [6]. The Art Council England stated that "Art and culture can be widely used to exert its lasting influence". It is convinced that art will shape people's values and behaviors in the future. The British Association of Arts and Business proposed that art and business have begun to emphasize the value reciprocity of professional exchanges. Recent research showed that both classic and current art is highly involved in the commercial market [7]. With concepts changing over time, art has become an important part of life aesthetics in people's daily lives. The commercial functions of art that are provided to the public have begun to be widely used; the social functions that are conferred by art have gradually been received. A current area of interest is to determine how to solve social problems more effectively so that art has more powerful value and development possibilities.

Based on the argument of social enterprises, a more inclusive concept of social innovation has been developed. The focus is no longer limited to the enterprise; the concept has been expanded to innovative products or services that solve social problems through the business model. The difference between social innovation and social enterprise is that a social enterprise is a single entity that uses commercial power to perform social missions; social innovation is the creation of society through the cooperation of technology, resources, and communities [8]. The integration of related resources is strengthened to establish a complete social innovation ecosystem. In other words, social innovation is a long-term value co-creation process that benefits the social system [9].

Social innovation creates a new type of social influence in which uses innovative methods to change the attitudes, cognition, and behaviors of actors related to social issues and the associated social context so as to develop a more profound and long-term social impact. Therefore, social innovation is no longer limited to the products or services of enterprises but is expanded to their social influence and generated social value. Thus, its value will not only benefit a single individual or organization but the entire social system.

Art creation is accessible to almost everyone. As such, a current trend is promoting the combination of art creation with other fields, and developing the possibilities and value generated by the interactions between art and other fields. Additional value is created through innovation in which contributions are more in line with societal needs. The performance of creation by an individual is a relatively complex psychological phenomenon and behavioral process that involves the individual's rational thinking and cognition of things through understanding the process of feeling.

The social innovation of art in the market is a relatively new concept. Its aim is to develop innovative business models to solve social issues using art creation as the core; at the same time, the organization can create economic value and obtain profit to achieve a sustainable business model. Art-creation enterprises are evidence of the social innovation of art and culture; they use the process of art creation as a medium to provide services. Through the freedom of art, consumer participation can be improved, and self-emotional mediation can be achieved in the process. In a broad sense, these enterprises provide specific social value [5]. The quantified nonspecific value is the social influence provided by artistic/creative enterprises. Although there is no universally applicable definition, and it is a relatively new concept. The development of those enterprises has considerable 
potential in the both the academic field and has practical industry implications. As such, the first research question was:

RQ1: What is the relationship and connotation of service innovation with the creation of painting enterprises' firm specific advantages?

\subsection{S-D Logic in Economic Value for Service Innovation}

Vargo and Lusch [10] reported that all economic behaviors should be regarded as services and proposed the service-dominant logic (S-D logic) centered on services. The concept states that service is the basis of all economic transactions and value is created through the application of resources to practices that are formed by co-creation [11]. Servicedominant logic emphasizes that, in the transaction process, the specific commodity is only a vehicle for providing the service, so the service provider cannot directly produce value. The benefits of service provision are the experience and solution in the service process, that is, its value is formed by the co-creation of the service providers and the receivers. Consequently, the service receiver, usually considered as the customers, is regarded as a co-creator of value.

Service design is increasingly considered an intentional channel to service innovation as it integrates a service perspective with a design approach [12-14] and is not just a simple design method. The relationships between service design and service innovation seem to be fundamentally overlapped within the service system. The view of service-dominant logic is that the true value of services is generated by value-in-use or value-in-context, rather than value-in-exchange [15]. Therefore, the service receivers are regarded as key members in the value-creation process, which allows service providers to provide innovative service experiences with different thinking and perspectives. Vargo and Lusch's [15] latest update to the S-D logic perspective of value co-creation states that direct and indirect interactions occur among all the actors, such as suppliers, third parties, and customers within the service ecosystem. Furthermore, value propositions are co-produced through purposeful collaboration; value is created only when the customer is using the solution provided by the supplier in a specific context [15]. Within the service-dominant logic concept, service receivers are one of the intangible resources of service providers: the perceptions provided by users based on their own needs, cognitions, expectations, or experiences play an important role in the value-creation process. The value proposition in the service process is provided by the service provider and evaluated by the service receivers.

Service innovation can be classified through the value theory of S-D logic based on two dimensions: the degree of value co-creation and the degree of network collaboration. Four types of service innovation have been proposed: (1) traditional innovation, with a focus on product-based innovation through improving quality and reducing costs, (2) collaborative innovation, with a focus on process-oriented innovation, through outsourcing relationships with other organizations and establishing cooperative relationships, (3) customer-oriented innovation, which focuses on strengthening the interactions between enterprises and customers, or between customers and customers through the network model and (4) serviceoriented innovation, with a focus on maximizing the value of the service economy, which is the highest degree of value co-creation and network collaboration [16]. This concept emphasizes that customers are value co-creators, and the joint participation of enterprises and customers is an important aspect for value co-creation in the service industry [17]. Furthermore, collaboration includes all internal and external actors that are connected to each other in all service networks [18].

The concept of open innovation, i.e., IOI-based systematic innovation, states that internal and external ideas are combined in systems whose requirements are defined by a business model [19]. Open innovation is a model that allows for a two-way flow of knowledge from inside the firm out (outbound) and from outside in (inbound) [20]. Research has shown that managerial innovations result in alterations to existing working patterns, systems, procedures, and style, resulting in efficiency and effectiveness in the delivery of services. Two critical areas were shown to provide efficient service in performance: the 
fundamental rethinking of the definition of service and the radical redesign of business processes [21]. In order to improve a service, remarkable innovations that break away from the old methods are needed and newer ones must be adopted. Research found that IOI innovation is a useful tool for enhancing business performance. Service innovation is a systematic innovation concept that is a bottom-up, transition-based system innovation concept [22]. This situation led to the second research question:

RQ2: What analytical frameworks are appropriate for constructing a service innovation model of painting-creation enterprises?

\subsection{Value Co-Creation in The Experience Economy}

Value co-creation is an actor-to-actor process [23]. The degree of co-creation can be divided into two primary conceptual dimensions: co-production and value-in-use [24]. In value co-creation, the consumers (service receivers) usually play an active role and co-create value with the firm (service providers) through direct or indirect collaboration in different stages from the production line to consumption [17,25-27]. The stages of engagement, interaction, self-service, and experience are considered the most crucial elements of value co-creation [28]. Furthermore, studies showed that value co-creation can be extended beyond the production chain to the consumption and value delivery chains through the entire service process [24]. Value-in-use is the customers' experiential evaluation of the product or service proposition beyond its functional attributes. This concept is also highly connected to customers' individual motivation, specialized competences, actions, behaviors, and so on. Furthermore, because the cooperation management affects how all the resources are integrated and value is co-created, diffusion is considered a co-creative process that involves multiple actors integrating new resources [29].

Experience is an abstract concept. Its realization is achieved by companies through using services as a platform, commodities as a medium, and consumers as the center to create memorable activities that can be more humane and sensible through service design. Through experience, the concept of service can be fully accepted, and the experience can create a lasting memory at the spiritual level for the customers. Furthermore, based on the idea of experiential service, if the five senses inform service encounters and serve as touch points, it can transform the service system into one that benefits all the actors in the system [30]. In the era of the experience economy, the core of service innovation is how companies use products or services to achieve individual goals for consumers. The main manifestation of economic value should be the experience value of consumers [31]: this view emphasizes the value of the emotional experience of cognition [32]. The importance of experience in economic activities relates to the value obtained from the service context. After countless experiences, memories naturally form and remain in people's minds. Memory is a comprehensive form of experience that is more characterized by emotion and ideology [33].

In today's society, consumers are not only pursuing physical needs, but also paying more attention to the psychological and social consumption experience. It means that they also have higher consumption consciousness. Research has shown that incorporating arts and culture into sustainable service design can generate added value and special experience for customers [30]. Companies with different value propositions provide different service experiences and cognition and create different consumer expectations. Value-in-experience is the enhancement of value-in-service. Consumers obtain value from their inner feelings through the service provided by the enterprise, which is a kind of spiritual satisfaction at the consumption level. With rapid economic and technological development, all aspects of life are becoming digitalized. However, people are more eager for physical interaction experiences. Painting is a simple act of human artistic creation. Because of the understanding of human nature through art, the operation of society has created close connections between people and art creation. Painting creation as a service for the core of the business offering is based on the purely innovative ideas of leisure and entertainment activities that are relatively cheap and easy to start. Nowadays, the service has been developed to 
contribute to the relief of emotions, demonstrating an instance of service innovation. Last but not least, the third research question was:

RQ3: What are the service experiences and effectiveness that co-create value in the service process from the creation of painting enterprises?

\section{Methodology}

\subsection{Research Design}

This research was mainly conducted to explore how the concepts of service innovation are integrated in companies that provide artistic painting as their service, and to explore how consumers evaluate their experience value, as well as achieve value co-creation through the service process under the service innovation model. In this research, I focused on the questions of how and why, with the enterprises' business model forming the main body of the study. For this type of study, the suitable methodological approach is the multiple case study method [34]. The research objects were mostly corporate representatives, and the research involved the analysis of multiple theoretical concepts. For the case study type, I used a multiple-case embedded design. I applied a detailed multiple-case CEO-interview-based methodology with four painting creation enterprises as the research objects. By exploring the firm specific advantages of these businesses, service design, service innovation, and social innovation as the research objects, I collected, summarized, and analyzed the data and noted the similarities and differences. The logical sequence of the conclusions established related theoretical explanations that show that the research results are relatively effective and applicable.

\subsection{Case Selection}

Four representative enterprises that met the inclusion criterion of being a domestic painting creation business were included in the study. As the objects in a study with multiple-case analysis design, I included two social enterprises and two for-profit enterprises. Because these painting creation enterprises can develop into social innovation enterprises, I chose both social and for-profit enterprises for the comparison of the differences in corporate organization.

I conducted in-depth case studies on each enterprise's founder or main operator. The four cases align with the thematic analysis of the research and were all shown to have good business and corporate management performance. The companies providing the creation of artistic paintings as a service are relatively new. However, as a relatively new type of industry, it has no clear definition or standard. Therefore, in the selection of cases, I selected industry elites who provided painting creation services as an innovative service in the Greater Taipei area. The companies all needed to be operating for more than five years. In addition to the differences in corporate organization, the actual processes of providing painting creation and service innovation have a considerable degree of homogeneity. It could provide effective research information for this study as a discussion on the connotation and process of service innovation and the establishment of specific practices.

\subsection{Data Collection and Analysis}

In this study, I adopted qualitative analysis methods to conduct case studies, collect interview data, and analyze and explain the characteristics of the cases based on theory. By constructing a research model, the work in this study was divided into four stages: exploration, description, comparison, and verification. Data analysis involved summarizing and qualitative content analysis [35]. The following steps, which were also used in the case studies reported by Rachinger et al. [36], were applied: (1) establishment of a provisional coding scheme: the initial coding scheme was derived deductively based on theoretical considerations; (2) paraphrasing: the original transcripts of interviews were used and paraphrased; (3) inductive coding of the data gathered: all interviews were coded according to the previously developed coding scheme; and (4) data analysis: after the coding, the data were analyzed by aligning the empirical results with the theoretical considerations. 
The main information for the semi-structured interviews in this research was obtained from founders who were actively involved in the service process of the business. For the interviews, I chose suitable industry elites as the interview subjects based on the literature review and the related information was provided. First, I used e-mail or telephone contact to identify those willing to be interviewed. Before carrying out the interview, the interview outline was provided to the interviewees. If the interviewees had any further questions, assistance answers were provided through e-mail. Originally, I adopted personal faceto-face interviews, and open-ended audio recordings were created during the interview process. However, due to the COVID-19 pandemic restrictions, some of the interviews were conducted online. The main aim was to use the interview questions as an outline; however, open and follow-up questions were permitted without limitation. The process focused on asking questions in key research directions while preserving the space and flexibility for the respondents to answer. The interview time for each interviewer was approximately sixty to ninety minutes.

Four semi-structured interviews were conducted in total and together with other secondary documents provided by the interviewer. As the result, a good amount of rich data was obtained. After the interviews, the interview recording files were converted into verbatim manuscripts. After the verbatim manuscript was completed, it was sent to the interviewee to review the content and confirm that the content of the verbatim manuscript matched their original intent in the interview before coding the verbatim manuscript. The data were systematized afterward in order to conduct within-case and cross-case analyses [37]. Based on the combined data collected through interviews and the literature review, I first examined the data collected for credibility, reliability, verifiability, and relevance quality criteria. The internal and external validity and reliability of data can analyze through triangulation-literature discussion, in-depth interviews, and practical observation [34]. Second, I organized and classified the data, and established a case database to systematically aggregate the data. The cases were described and analyzed based on theory; the secondary analysis was performed between cross-cases to strengthen the correlation and complementarity of the data. Furthermore, I followed the theoretical framework of this research by applying cross-case analysis for a cross-case comparison. Finally, I elaborated and explained the evidence presented in the collected data, and conducted an empirical analysis to conclude the case study.

\section{Case Overview}

\subsection{Social Entertainment Enterprise Co., Ltd.}

Social Entertainment Enterprise Co., Ltd. was the first social enterprise in Taiwan to promote art creation and aesthetics education. Its service target is mainly elementary school children. The core concept of the company is to help more people be happy and less depressed. The founders combine public welfare with commercial methods and address social issues through marketing that hopes to make the world happier and reduce the depression rate in society. The company brings artists to various schools to teach painting and to provide emotional relief for the participants. The company firmly believes that, if the general public can understand emotional problems and cultivate children's healthy and emotional relief concepts and methods from childhood, the social problems caused by emotional depression can be significantly reduced.

\subsection{New and Alive Art Service Co., Ltd.}

New and Alive Art Service Co., Ltd. was the first social enterprise in Taiwan to provide creative services for the elderly. The core concept of the company is "In art, we are new and alive". The founders formally introduced the idea "Elders Share the Arts" (ESTA) from New York in 2005, combining inherited art with the concepts of oral history and creative ageing. In addition to responding to the lack of social participation of the elderly, they aim to strengthen the creative and energetic image of the elderly. Through the creation of paintings, the elderly can overcome physical or psychological communication barriers and 
intuitively record their own stories and thoughts. Through specialist training, planning design, and service material provision, the company uses its innovative business model to bring creative services to the elderly and society.

\subsection{The Escape Artist Co., Ltd.}

The Escape Artist Co., Ltd. was the first entertainment painting space in Taiwan that combines a painting studio with a café atmosphere. It created a new concept for entertainment venue in the Greater Taipei area. The core concept of the company is to provide a space for users to enjoy free creation. They hope that, through actions, people will feel their own creativity and that of life, so as to attract more people to be interested in the coexistence of art and life. The founders also hold the belief that art is infectious, which is the concept of force management, that is, turning "art" from a noun into a verb and truly entering our lives. More than $80 \%$ of their customers aim to purely enjoy the fun of free creation. This space is not a studio, not an art gallery, nor a coffee shop, but a new concept of entertainment creation space for using paint as a medium to let consumers have fun: a kind of entertainment service industry that heals the soul.

\subsection{Pearl Studio Ltd.}

Pearl Studio Ltd. was founded by a founder who had been engaged in performing arts and painting for many years. It first started as a personal studio, which was influenced by the popular European and American art leisure activity known as paint and sip. Gradually, it transformed into a fusion of art, fashion, and creation, with wine tasting and music. The core concept of the company is to provide an artistic service space where people can create freely and enjoy wine tasting. The founder firmly believes that art can provide healing power, positive energy, and curiosity. Through the process of painting, organizing thoughts, sharing observations of beautiful things, and integrating accumulation and emotions in life into every creation is the business goal of the company.

\section{Findings}

5.1. The Relationships and Connotation of Service Innovation with Painting Creation Enterprises' Firm Specific Advantage

The interviewees, who were the operators of the four companies, all expressed that the original core concept for the establishment of the company was not profit-oriented. Through their own observations, the motivation for the establishment of the company using artistic painting creation as the business model was a practical solution that addressed the observed social problems. In the analysis of the relationship between the company's firm-specific advantages and service innovation, the research found that the essence of the company and the personal characteristics of the operators deeply influenced the core value propositions of the enterprises. Because enterprises with this kind of business model usually start from a non-profit point, their core value behind business operations is beyond the material economy.

Research also found that the operators could all clearly state the core values of their companies and could fully explain how they achieve their original intentions during their development process. They used different strategies to adjust their business models, which all had an obvious influence on social consciousness. Different social issues were solved both tangibly and intangibly, which also showed that their corporate value propositions have produced different levels of social contribution. Through the interview process, the research concluded that their consumption model differs from the product-oriented model. The service-oriented business model is more unique and not as easily replaced. Through the supply and acceptance of value in the service sector, it is easier to develop a diversified orientation, which provides enterprises with various potential business models within an industry, so as to achieve the goal of sustainable operation. The research findings showed that painting is easy and is suitable for mostly everyone, from children to the elderly. It is a service that is easily accepted by the public. 


\subsection{Service Innovation Model for Painting Creation Enterprises}

Most of the painting creation enterprise owners had non-profit concept as their original intent for starting a business. However, in addition to a clear value proposition, they also had to consider the reality. The arrangement of internal and external business strategies, and the composition and management of the core team are important key factors in business operations. The planning of internal business strategy includes organizational culture, human resource allocation, financial modelling, and technological applications. The external business strategy uses available business partner resources as a supplementary source for the business operations.

Through the interviews, the research concluded that the enterprises' choice of their service objects directly affected the content of their services, especially the environmental atmosphere created in the space. It was found to be a significant influencing factor, because this type of service involves experience and psychological feelings that are different from product services. Service providers need to thoroughly plan the concepts and processes that are suitable for the service receivers. A different finding was the degree of interference in service content. Only one of the four companies had a low degree of interference in the value co-creation of the service. However, as measured by the application of its service concept, this company can still provide services that conform to the corporate philosophy. Therefore, in terms of the value co-creation in services, the service receiver's performance plays a key role.

Service innovation in business, in addition to using appropriate tools to explore the consumers' situation, can be used to observe and experience the actual feelings of consumers. Through the interviews, the research found that the designs of the artistic paining creation experiences were diversified. Additionally, the key factors were inextricably related to the core value of the enterprise. Another special finding was that service innovation in the business that use painting creation as a medium pays special attention to the impact on consumers after the service experience. All four companies claimed that it is not only the current experience, but also the service that can have a long-lasting impact. Painting is an activity involving human instinct. The service process experience designed by these enterprises awakens the memory of human beings, which is a major feature of painting creation as a service.

\subsection{The Value Co-Creation through the Service Experience and Its Effectiveness}

The degree of value co-creation is an important factor affecting service innovation, and resource integration is the most economical method to practice value co-creation and sharing. Through the interview process, the research concluded that the degree of resource integration of the painting creation enterprises was its degree of network collaboration in terms of value co-creation indicators. Based on the integration of resources generated by different service actors, network collaboration has become the most practical channel through which companies create additional value beyond their core values. Through the analysis of the data obtained in the interviews, the value co-creation of the service innovation process can be further subdivided into co-design, co-produce, and co-delivery.

Three of the four companies confirmed that different degrees of cross-industry cooperation can help companies create added value in order to help the company adjust their original service design process to achieve better result. This not only optimizes the original design level, but also provides a more appropriate service experience, and can help with the development and design of potential various-oriented services. Cross-industry cooperation also helps to expand consumer sources, which is key for companies to maintain sustainable operation. The interviews showed the practical implication of this process that was based on theoretical research, which creates a larger scope for future research.

Summarizing the four companies through reviewing the concept of after-sales service, the research concluded that painting creation, as a service, not only provides value cocreation but also value co-sharing through the service experience. Through the interview process, the research found that the value co-sharing of painting creation enterprises lies in 
the satisfaction at the spiritual level and the sense of joy created by the service. Different from the concepts of product-oriented services, this is the value that can be produced only when the service experience is appropriately oriented. From individuals to the whole of society, the four companies all expressed optimism in this regard. Because of this value co-sharing, the connection between the enterprise and the consumer is strengthened. In other words, value co-sharing also enhances the sustainability of the operations of the enterprises.

\section{Discussion}

Through interviews with the operation management of painting creation enterprises, the research found that the degree of service innovation is closely related to the essence of the company and the personal characteristics of the founders. Precisely because of the provision of painting as a service in which there is a service-oriented supply, the core value of the enterprise is created through the effectiveness of the internal management and the external links. Through the interviews, in addition to the commercial value of the corporate model, the research identified additional corporate values, such as emotional healing, creative ageing, creativity, and sense of accomplishment. The research findings showed that art organizations participate in co-creating value with customers, providers, and other stakeholders; the processes is conceptualized within a service system [38]. Through interviews, the research found that value is co-created in various stages from service delivery to service acceptance among all the actors. The similar outcomes regarding the degree of co-creation could be categorized into two primary conceptual dimensions: coproduction and value-in-use [24]. Value-in-use was considered in terms of co-experience and the relationships in the network created through the service process.

The scope of service innovation for enterprise management is extensive, from organizational culture, human resource allocation, financial model, service delivery, and technology application. Previous research showed that the use of the concept of the service system in the dynamic and interdependent network of people, technologies, and various recourse that interact with other service systems to create co-value considers this system as a broader phenomenon [39]. Companies that provide painting creation as their service are relatively new business models. It is crucial to understand how to plan and adopt appropriate service innovations to effectively assist the sustainable operation and management of the company. Research showed that IOI innovation is a useful tool to enhance business performance [21]. My results agree with those of this previous study, suggesting that although both input and output innovation are significantly correlated, some inside decisions have more significant effects on the service innovation of the business. Under the background in era of rapid advances, being able to accurately and quickly replace strategies and grasp market trends are key factors for a new business.

Through the interview process, the research concluded that painting creation enterprises all have a clear definition of their organizational culture. All four companies reported that they pay special attention to their connection with people, because these companies are usually composed of small and sophisticated groups of people. Research on the value co-creation process also showed that some small and medium sized enterprises are usually more rigorous about their service performance [40]. What matters is not the number of people in the organization, but whether each partner understands, accepts, and implements the unique organizational culture of the company. Because of the small number of people in the company, more attention is paid to the relationship with each other. This concept is not just applied to the internal team but also to the services provided by the enterprises. Recent research reported that in the age of digitalization, service design is focusing on intra-organizational processes and service delivery, with limited attention being paid to the actual user experience [41,42]. However, a special finding is that service innovation in businesses that uses painting creation as a medium pays special attention to the impact on the consumer experience with the service. All four companies claimed that it is not only 
the current experience, but also the long-lasting impact of the service are their aims, which is an important factor in experience economy.

Nowadays, in this digital era, whether it is a brand-new industry or a traditional industry, the application of technology needs to be considered. However, through the interviews, the research concluded that companies that offer painting creation as their service are running in the opposite direction. Because the value provided by these services are closely related to the human experience. All four company interviewees indicated that the application and practice of technology is not too important for them at this stage. Recent research showed that value creation includes two aspects: co-production of the value proposition and co-creation of the value experience. Hence, the co-production of value propositions and the use of the solution are the sub-processes of value co-creation [40,43]. Although technology can solve some of the problems faced by these companies, such as distance barriers, the research showed that value co-creation is related to situations where the customer and the supplier together generate the customer experience [40]. Recent research showed that the design of the experiential service settings for service encounters is a form of value creation [30]. The actual interaction and the experience from the service created by the physical environment are more necessary for the painting creation service. As shown by recent research, service delivery must occur when the service providers offer the value proposition, which the service users may then integrate into their value creation process $[44,45]$. At this stage, technology still cannot provide perfect assistance for the integrity of service delivery. While almost everything in our everyday lives is integrated with technology, the physical consumption of painting creation has instead injected a relatively human lifestyle and has enriched the value of the experience economy.

\section{Conclusions and Implications}

\subsection{Conclusions}

The aims of this research were to explore how to integrate the concepts of service innovation with companies providing artistic painting creation as their service offering in their business model and to explore how consumers evaluate their experience value as well as achieve value co-creation through the service process under the service innovation model. In this study, the research incorporated the viewpoint of art into the service science field and combined creative and innovative thinking with business operations. The outcome provides a practical implication for business structures by indicating the importance of enhancing social value and co-creation during the development of creative industries. The healing value of painting creation as a service is a natural and unavoidable side effect, because it is an ongoing industry in the market. The research found that painting creation as a service has an obvious influence on social consciousness, and invisibly provides part of a solution to different types of social issues. It also showed that corporations' different value propositions provide different levels of social contribution and innovation. There is also a phenomenon of supply and demand reflected in the current market. Therefore, this field is worthy of more in-depth discussion.

Painting is one of humanity's original entertainment methods, together with singing and dancing. The corporate model of painting creation serves to provide the general public with the opportunity to experience original essence of painting. In the process of free creation, emotional healing and stress relief can be achieved, and creativity can be cultivated and enhanced in the process of starting from nothing. The whole process satisfies the sense of accomplishment that modern people seldom feel by themselves. The happiness produced by painting creation extends to the development of service innovation. This industry that takes altruism as the starting point in order to further develop. Painting can be a creative force providing a bridge for humans to communicate among themselves. Additionally, the power of painting can also create a connection with others in life. In conclusion, the popularity and easy accessibility of using painting as a service reinforce the use of painting creation to create internal expression channels that can be used as service 
innovation for businesses in the creative industries and showed the potential for future development.

\subsection{Theoretical Implications}

Service innovation is a mode of innovation. Service design is a method of design thinking. Most research fields in service science think that service design can further promote the practice of service innovation. However, the research found that the relationship between them does not only exist in a single direction but overlaps each other. Service design is the index of S-D logic and value co-creation, for which research showed that a certain degree of value exists in co-design, co-production, and co-delivery. Service innovation is an indicator of the coordination and integrity of the entire service network system. The findings showed that there can be innovative strategies in internal operations, external integration, or cross-industry cooperation The more complete the development of resource integration, the more effectively service innovation is achieved. Not only is value co-created in the service production process, but it can also be created in service delivery and service acceptance.

\subsection{Managerial Implications}

The research findings showed that because of the user-friendliness of painting, crossindustry cooperative relationships can easily be developed such as aesthetic education, joint branding of paintings and products, corporate education and training, design plan, etc. From an economic perspective, in the era of the experience economy, creation of paintings as a service shows optimistic future development. The research also found that companies that provide painting creation services, regardless of whether the company is for-profit or not, all have a high degree of social responsibility and participation. Painting is a relatively easy channel to allow art to penetrate everyday life. Long-term development also has a positive influence on the art acumen and is appreciated by the public. Social enterprises are based on the type of enterprise that provides solutions to certain social problems. Therefore, these companies have a higher chance of needing to make a trade-off between adherence to the core values of the enterprise and government economic assistance. As a result, the enterprises' sustainability of operation is relatively dependent and is less controlled. Therefore, it is necessary to take a closer look at how to implement those suggestions in future practice.

\subsection{Limitations and Futhure Resarch Directions}

In terms of research design, the research only considered service providers as interview subjects, but not service receivers. It could not determine of service receivers' feelings with the primary data, as the secondary data could not provide direct information from the service receivers. It is inevitable that there will be differences in viewpoints. Thus, this is one limitation of this study. In addition, this research was limited by the research objects and research resources, so only enterprises in the Greater Taipei area were the interview subjects, which is the second restriction. Therefore, I hope that painting creation enterprises in Taiwan can develop increasingly and vigorously, so that more professionals will participate in both the academic field and the industry to enable more diversified and in-depth research in the future.

In this research, it discussed the possible directions for further research and provided suggestions for an extended study of the painting creation service. The first is the strategic development for the application of a service in the experience economy to society. In the experience economy, service actors implement the business strategy providing a service value exchange, and then achieve the benefits of social value co-creation. The second is the conceptual practice of combining creative industries with service innovation. This research provides different-oriented business models for creative industries. In addition to economic value, other positive added value is provided to society. Companies provide service 
innovation in different forms and have various development possibilities for different types of enterprises, which can be extended to achieve the vision of social innovation.

Funding: This research was funded by the Higher Education Cultivation Project under National Taiwan University of Arts.

Institutional Review Board Statement: Not applicable.

Informed Consent Statement: Informed consent was obtained from all subjects involved in the study. Data Availability Statement: Data were contained within the article.

Acknowledgments: The author would like to extend the deepest gratitude to Chun-Liang Chen for his invaluable assistance on preparing the article. The author would also appreciate all the interviewers for their valuable contributions to the research.

Conflicts of Interest: The author declares no conflict of interest. The funder had no role in the design of the study; in the collection, analyses, or interpretation of data; in the writing of the manuscript; or in the decision to publish the results.

\section{References}

1. Tolstoy, L. What Is Art. Bobbs, 1st ed.; Merrill: Indianapolis, IN, USA, 1960.

2. Phills, J.A.; Deiglmeier, K.; Miller, D.T. Rediscovering social innovation. Stanf. Soc. Innov. Rev. 2008, 6, 34-43.

3. Snyder, H.; Witell, L.; Gustafsson, A.; Fombelle, P.; Kristensson, P. Identifying categories of service innovation: A review and synthesis of the literature. J. Bus. Res. 2016, 69, 2401-2408. [CrossRef]

4. Blomkvist, J.; Holmlid, S.; Segelstro, F. This Is Service Design Thinking, 1st ed.; BIS.: Amsterdam, The Netherlands, 2010.

5. Meroni, A.; Sangiorgi, D. Design for Services, 1st ed.; Taylor and Francis: Abingdon, Oxon, 2016.

6. McQuilten, G.; White, A. Impact and sustainability in art based social enterprises. In Research Unit in Public Cultures (RUPC) Working Papers Series; University of Melbourne: Melbourne, Australia, 2015; pp. 1-26.

7. Baumgarth, C.; Wieker, J.B. From the classical art to the urban art infusion effect: The effect of street art and graffiti on the consumer evaluation of products. Creat. Innov. Manag. 2020, 29, 116-127. [CrossRef]

8. Mulyaningsih, H.D.; Yudoko, G.; Rudito, B. Knowledge-based social innovation process in social enterprise: A con-ceptual framework. Adv. Sci. Lett. 2016, 22, 1393-1397. [CrossRef]

9. Voorberg, W.H.; Bekkers, V.J.J.M.; Tummers, L.G. Co-Creation in Social Innovation: A Comparative Case-Study on the Influential Factors and Outcomes of Co-Creation; Erasmus University Rotterdam: Rotterdam, The Netherlands, 2014.

10. Vargo, S.L.; Lusch, R.F. Evolving to a New Dominant Logic for Marketing. J. Mark. 2004, 68, 1-17. [CrossRef]

11. Vargo, S.L.; Lusch, R.F. Service-dominant logic: Continuing the evolution. J. Acad. Mark. Sci. 2007, 36, 1-10. [CrossRef]

12. Joly, M.P.; Teixeira, J.G.; Patricio, L.; Sangiorgi, D. Leveraging service design as a multidisciplinary approach to service innovation. J. Serv. Manag. 2019, 30, 681-715. [CrossRef]

13. Patricio, L.; Gustafsson, A.; Fisk, R. Upframing Service Design and Innovation for Research Impact. J. Serv. Res. 2017, 21, 3-16. [CrossRef]

14. Vink, J.; Koskela-Huotari, K.; Tronvoll, B.; Edvardsson, B.; Wetter-Edman, K. Service Ecosystem Design: Propositions, Process Model, and Future Research Agenda. J. Serv. Res. 2020, 24, 168-186. [CrossRef]

15. Vargo, S.L.; Lusch, R.F. Institutions and axioms: An extension and update of service-dominant logic. J. Acad. Mark. Sci. 2015, 44, 5-23. [CrossRef]

16. Nam, K.; Lee, N. Typology of service innovation from service-dominant logic perspective. J. Univers. Comput. Sci. 2010, 16, 1761-1775.

17. Payne, A.F.; Storbacka, K.; Frow, P. Managing the co-creation of value. J. Acad. Mark. Sci. 2008, 36, 83-96. [CrossRef]

18. Basole, R.C.; Rouse, W.B. Complexity of service value networks: Conceptualization and empirical investigation. IBM Syst. J. 2008, 47, 53-70. [CrossRef]

19. Fernando, R.L.S. Managerial Innovation in Service Delivery in Public Sector Organizations in Sri Lanka, Governance and Development; Shrabon Printing Press: Dhaka, Bangladesh, 2006; pp. 221-237.

20. Hochleitner, F.P.; Arbussà, A.; Coenders, G. Inbound open innovation in SMEs: Indicators, non-financial outcomes and entrytiming. Technol. Anal. Strat. Manag. 2016, 29, 204-218. [CrossRef]

21. Jehan, S.; Elapatha, V. Systematic Innovation Based BPR Regime-A Factors Analysis. Appl. Syst. Innov. 2020, 3, 50. [CrossRef]

22. Jehan, S.N.; Alahakoon, M.U.I. Digitalization of Public Services-An Input Output Logit Analysis. Appl. Syst. Innov. 2020, 3, 56. [CrossRef]

23. Lusch, R.F.; Nambisan, S. University of Wisconsin-Milwaukee Service Innovation: A Service-Dominant Logic Perspective. MIS Q 2015, 39, 155-175. [CrossRef]

24. Ranjan, K.R.; Read, S. Value co-creation: Concept and measurement. J. Acad. Mark. Sci. 2014, 44, 290-315. [CrossRef] 
25. Hoyer, W.D.; Chandy, R.; Dorotic, M.; Krafft, M.; Singh, S.S. Consumer co creation in new product development. J. Serv. Res. 2010, 13, 283-296. [CrossRef]

26. Roggeveen, A.; Tsiros, M.; Grewal, D. Understanding the co-creation effect: When does collaborating with customers provide a lift to service recovery? J. Acad. Mark. Sci. 2012, 40, 771-790. [CrossRef]

27. Tynan, C.; McKechnie, S.; Chhuon, C. Co-creating value for luxury brands. J. Bus. Res. 2010, 63, 1156-1163. [CrossRef]

28. Bendapudi, N.; Leone, R.P. Psychological Implications of Customer Participation in Co-Production. J. Mark. 2003, 67, 14-28. [CrossRef]

29. Vargo, S.L.; Akaka, M.A.; Wieland, H. Rethinking the process of diffusion in innovation: A service-ecosystems and institutional perspective. J. Bus. Res. 2020, 116, 526-534. [CrossRef]

30. Chen, C.-L. Strategic sustainable service design for creative-cultural hotels: A multi-level and multi-domain view. Local Environ. 2021, 27, 46-79. [CrossRef]

31. Prahalad, C.; Ramaswamy, V. Co-creation experiences: The next practice in value creation. J. Interact. Mark. 2004, 18, 5-14. [CrossRef]

32. Schau, H.J.; Muñiz, A.M.; Arnould, E.J. How Brand Community Practices Create Value. J. Mark. 2009, 73, 30-51. [CrossRef]

33. Harrington, R.J.; Hammond, R.K.; Ottenbacher, M.C.; Chathoth, P.K.; Marlowe, B. From goods-service logic to a memorydominant logic: Business logic evolution and application in hospitality. Int. J. Hosp. Manag. 2019, 76, 252-260. [CrossRef]

34. Yin, R.K. Case Study Research: Design and Methods, 3rd ed.; Sage Publications: Thousand Oaks, CA, USA, 2001.

35. Mayring, P. Qualitative Inhaltsanalyse. In Handbuch Qualitative Forschung in der Psychologie; Mey, G., Mruck, K., Eds.; VS Verlag für Sozialwissenschaften: Wiesbaden, Germany, 2010; pp. 601-613.

36. Rachinger, M.; Rauter, R.; Müller, C.; Vorraber, W.; Schirgi, E. Digitalization and its influence on business model in-novation. J. Manuf. Technol. Manag. 2018, 30, 1143-1160. [CrossRef]

37. Miles, M.B.; Huberman, A.M. Qualitative Data Analysis: An Expanded Sourcebook, 2nd ed.; Sage Publications: Thousand Oaks, CA, USA, 1994

38. Williams, M.; Biggemann, S.; Tóth, Z. Value creation in art galleries: A service logic analysis. Australas. Mark. J. 2020, 28, 47-56. [CrossRef]

39. Koskela-Huotari, K.; Patrício, L.; Zhang, J.; Karpen, I.O.; Sangiorgi, D.; Anderson, L.; Bogicevic, V. Service system transformation through service design: Linking analytical dimensions and service design approaches. J. Bus. Res. 2021, 136, 343-355. [CrossRef]

40. Royo-Vela, M.; Velasquez Serrano, M. Value co-creation process and measurement in 4.0 SMEs: An exploratory re-search in a B2B marketing innovation context. Adm. Sci. 2021, 11, 20. [CrossRef]

41. Eriksson, E.; Hellström, A. Multi-actor Resource Integration: A Service Approach in Public Management. Br. J. Manag. 2020, 32, 456-472. [CrossRef]

42. Trischler, J.; Westman Trischler, J. Design for experience-A public service design approach in the age of Digitalization. Public Manag. Rev. 2021, 1-20. [CrossRef]

43. Kohtamäki, M.; Rajala, R. Theory and practice of value co-creation in B2B systems. Ind. Mark. Manag. 2016, 56, 4-13. [CrossRef]

44. Eriksson, E.; Andersson, T.; Hellström, A.; Gadolin, C.; Lifvergren, S. Collaborative public management: Coordinated value propositions among public service organizations. Public Manag. Rev. 2019, 22, 791-812. [CrossRef]

45. Hardyman, W.; Kitchener, M.; Daunt, K.L. What matters to me! User conceptions of value in specialist cancer care. Public Manag. Rev. 2019, 21, 1687-1706. [CrossRef] 